\title{
CP VIOLATION WITHOUT ELEMENTARY SCALAR FIELDS
}

\author{
Estia Eichten, Kenneth Lane, ${ }^{*}$ and John Preskill
}

Lyman Laboratory of Physics

Harvard University

Cambridge, Massachusetts 02138

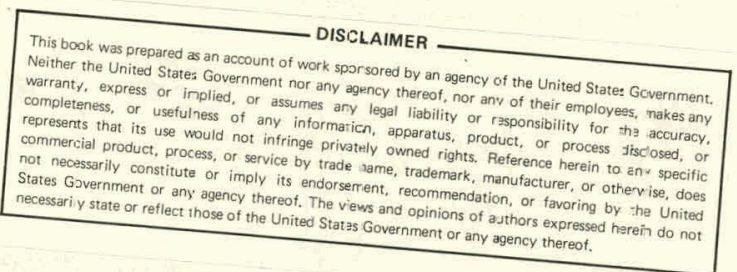

ABSTRACT

Dynamically broken gauge theories of electroweak interactions provide a natural mechanism for generating $\mathrm{CP}$ violation. Even if all vacuum angles are unobservable, strong CP violation is not automatically avoided. In the absence of strong CP violation, the neutron electric dipole moment is expected to be of order $10^{-24} \mathrm{ecm}$. 


\section{DISCLAIMER}

This report was prepared as an account of work sponsored by an agency of the United States Government. Neither the United States Government nor any agency Thereof, nor any of their employees, makes any warranty, express or implied, or assumes any legal liability or responsibility for the accuracy, completeness, or usefulness of any information, apparatus, product, or process disclosed, or represents that its use would not infringe privately owned rights. Reference herein to any specific commercial product, process, or service by trade name, trademark, manufacturer, or otherwise does not necessarily constitute or imply its endorsement, recommendation, or favoring by the United States Government or any agency thereof. The views and opinions of authors expressed herein do not necessarily state or reflect those of the United States Government or any agency thereof. 


\section{DISCLAIMER}

Portions of this document may be illegible in electronic image products. Images are produced from the best available original document. 
In thls letter, we show that there is a natural mechanfom for generatIng CP violation in dynamlcally brokell electroweak gauge theorieg. Our proposal requirea no new gauge intẹractions beyond those discussed prevlously. ${ }^{-t}$ Spontnneous CP violation crn appeur when we carry out Dashen's procedure to Identify the correct chtral vacuum. Wietler CP violation occurs lo jeccroined in principal by only the gauge group and the fermion representation content of the theory.

These theories have no elementary scalar f1elds and no fermlon bare masses. Even though there are nu observable vacuun angles, 6 atrong $\mathrm{CP}$ vlolation'1s not automatlcally avolded. We state a criterion for the absence of strong CP violation; If it 18 untisfled, CP violating phases In the quark miss matrix are naturally suppreseed by a factor of order $10^{-9}$. Additional CP violation appears in the electroweak Interaction and in the gauge interaction responsible for chlral symitry breaking. We predict that the electric dipole moment of the neutron 18 of order $10^{-2} \mathrm{ecm}$.

In a theory of weak Interictions without elementary scalar flelds, a new gauge Interaction"t ("hypercolor", wh gallge group $G_{11}$ ) is required, In addition to the familiar color $\left(C_{C}=\operatorname{sU}(3)\right)$ and electruweak $\left(G_{W}-\operatorname{SU}(2)\right.$ $\times v(1))$ Interactions. Hypercolor becomes a strong interaction at a mass acale $\eta_{H}=1 \mathrm{TeV}$, and drives the breaking of $G_{H}$ down to $U(1)_{E M}$.

A thicory with gauge group $i_{\|} \times C_{C} \times C_{W}$ alone cannot be renlistlc. A "yldewaye" interaction ${ }^{30}$ (with grnup $G_{S}$ ) ly needed to break explicitly all chiral Bywetrles not gauged by $C_{W}$. $C_{S}$ is dynamically broken to a subproup contalning $G_{11} \times G_{C}$ at a miss scale "s $=100 \mathrm{TeV}$. (We need not speculate here on the ordgin of the $G_{S}$ breakdown. $)^{4,9,10}$

All ferwlons are in at most four irreduclble representations of $G_{S}{ }^{*}$ In the effective gauge theory wilch describes physics below $100 \mathrm{TeV}$, each of these representations transforms reduclbly under $C_{H} \times G_{C^{*}}$ If we neglect. the broken sldeways interactions and the weak interactions, the $G_{11} \times G_{\mathrm{C}}-$ Invarlant effective Hamlltonian sf respecto a global (chiral) flevor-gymetry group $C_{f}, G_{W}$ 1s a subgroup of $G_{f}$.

when hypercolor and color becumo strong, $G_{f} 1.8$ dynamically broken to a oubgroup $S_{f}$. Many Coldstone bosons result. Three of these nre aiten by the weak $W^{ \pm}$and $z^{0}$ bosons. ${ }^{1,2}$ the remaining Goldstolle bosons acquite nass from the chiral symactry breaklng perturbation $K^{C}$ generated by the weak and sidaways Interactions.

The ground state of $K_{0} 18$ highly degenerate; the vacua are paramelrized by the coset space $C_{f} / S_{f}$. The perturbation $g C$ IIfts the degeneracy and pleks out the true chlral-perturbative vacuum, the limit of the, ground atnte of $3 \zeta_{0}+\varepsilon J C$ as $\varepsilon \rightarrow 0$. As Dashen' explained, we can Identify the correct vacuum by ofnimlzing an effectlue potential which, in lowcst order perturbation theory, 18 $\left.V(B)=\langle\Omega| U^{-1}(8)\right] c_{1} v(g)|g\rangle$.

Here $B \in C_{f}, U(B)$ represents $C_{f}$ in the HLIbert space of statcs, and $|\Omega\rangle$ lo the $S_{f}$-invariant vacuum. In the calculations described below, it 1 s conventent to regard the symmetry group of the vacuum as fixed. Then, from among all $G_{f}$-equivalent perturbations $J C^{C}(g)=V^{-1}(g) J C^{C} U(g)$, we choose that one which minimizes the energy of the $S_{f}$-invarinnt vacuum $|\Omega\rangle$.

Now we sce how apontancous CP violation can nrise naturully. Wo nssume that the fermion rupresentation cuitent under 6s is such that ald 6s vacuum angles ${ }^{6}$ can be simultancously rutated to zero, and hence are unobservable. In particular, $C_{S} \mathrm{mlght}$ be almple." We further asoume that the bruaking of $a_{s}$ does not introduce $c F$ vlolation, so that the effective gauge theory below $100 \mathrm{TeV}$ 1s CP-Invariant. 12,13 Thus the vacuur $|\Omega\rangle$ and the perturtation $X^{\prime}$ are CP-Invarlant, and the effective potential 1o CP-eymetric. Howcver, the 
energy might be winlmlied by a CP-vlulating $\mathrm{JC}^{\circ}(g)$; then $V(g)$ has a degenerate oInimum, and CP Is opontaneously broken." The mInImum of $V(g)$, and whether epontaneous CP violation occurs, is determined once the pattern of $C_{s}$ ald $G_{f}$ breaking is known.

The approximate flavor group $G_{f}$ is determined by the $\sigma_{11} \times \sigma_{C}$ representation content of the fecmlons. We will assume that all nontrivial representations of $G_{H} \times C_{C}$ are complex, that the color and hypercolor Interactlons are vectortal, and that the maximal isospln Is left unbroken when hypercolor and color get strong. (These assumptions ensure that $G_{W}$ breaks down to $U(1)_{Q 1}$ ' and that the relation $\mathrm{M}_{W} / \mathrm{H}_{2}=\cos _{W}$ is satisfied. ${ }^{2}$ ) Then the fermions may be denoted $\psi_{L r 1}^{(\rho)}, \psi_{\operatorname{Rr} 1}^{(\rho)}$. The Index $\rho$ Ident ffles the trreduclble representat lon $\Sigma^{(p)}$ according to vilch $\psi^{(\rho)}$ transforms under $\sigma_{11} \times \sigma_{c}$. The gauge group $\sigma_{11} \times$ $c_{c}$ acts on the Index 1. The Index $r\left(r-1,2, \ldots, n_{p}\right)$ labels the various flavors of fermlong whlch trensform as the representation $\mathfrak{J}^{(\rho)}$.

The flavor group is

$$
c_{f}=\prod_{\rho}\left(\operatorname{su}\left(n_{\rho}\right) \times s U\left(n_{\rho}\right) \times v_{V}^{n}(1)\right] \times v_{\Lambda}(1)^{\prime} B .
$$

whlch breaks down to $s_{f}=\prod_{\rho}\left[S U\left(n_{f}\right) \times u_{v}^{\rho}(1)\right]$. Under $G_{f}$, the fermluns trunsform as

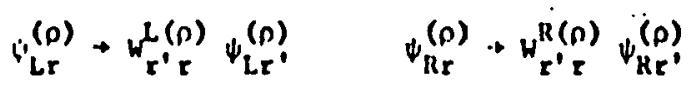

where $w^{L(\rho)}$ and $w^{K(p)}$ are unltary $n_{\rho} \times n_{p}$ matrices. If $s_{f}$ la the diagonil subgroup with $w^{\downarrow}=w^{R}$, then the elements of $G_{f} / S_{f}$ can be labeled by a set of unltary aatrices $\left(w^{(p)}-W^{L(p)+} W^{R(p)}\right\}$.

Each representurion $\tau^{(\rho)}$ of $C_{H} \times C_{C}$ has $n$ hypercolor and color anomaly Blven by

$$
\partial^{\mu} J_{S \mu}^{(\rho)}-T_{p}^{H} \frac{R_{H}^{2}}{8 n^{2}} \operatorname{tr} F_{H} \tilde{F}_{H}+T_{p}^{C} \frac{f_{C}^{2}}{8 \pi^{2}} \operatorname{tr} F_{C} \tilde{F}_{C}
$$

where $T_{D}^{H}\left(T_{\rho}^{C}\right)$ la the erace of the square of the hypercolor (color) genierators Io the representation $2^{(D)}$. (We have assumed that $G_{H}$ 18 simple.) All linear combinations of the $J_{S_{1}}^{(p)}$ 's with vanlshing hypercolor and color anomolles generate $U_{A}(1)$ sysanetries witch are included in $G_{f}$. Because $G_{f}$ contains only anomaly-free $U_{A}(1)$ factors, the $W^{(\rho)}$ 'o satisfy the conotraint

$$
\prod_{\rho}\left[\operatorname{det} w^{(\rho)}\right]^{\mathrm{T}_{\rho}^{H}}=\prod_{\rho}\left[\operatorname{det} w^{(\rho)}\right]^{\mathrm{T}_{\rho}^{\mathrm{C}}}-i \text {. }
$$

The weak Interactions play a accondary role in determinlng the mintonum of the effective potential; 15 we need sconsider only the broken sideways Interactions. We Integrate out the mabsive gldeways gauge bosons to obtaln a $G_{H} \times G_{C} \times G_{W}$-invariant ef fective Lilgranglan. The leading $C_{f}$-brenklug terms In the effectlve Lagranglan are four-ferrion operators. Iligher dimenston operntors are suppresied by additlonal powera of $\mathrm{m}^{-1}$. We almplify the discussion by assuming that $S U(2)_{W}$ commutes with $j_{S}$, so that thete 18 in exinct global $U(1)$ eymetry which distingulshes wenk doublets from weak singlets. After plere rearrangements, the most general four-fermion operator Invariant under $G_{H} \times G_{C} \times G_{W}$ and the global $U(1)$ witch contriliutes to the effective potential has the form

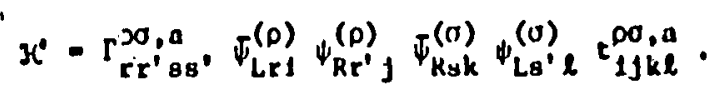

Here the $t_{1 j k \ell}^{1.0, a}$ are $a_{11} \times G^{-1 n v a r 1 a n t}$ teasore, Indexed by $a$, and $r_{r r^{\prime}}^{n o, a}$, $O\left(m_{B}^{-2}\right)$ lo a $C_{W}$-lnvariant censor which can be calculated to artitrary order In the sideways coupling $g_{B}^{2}$. To luwest order in $B_{B}^{2}, K^{+}=g_{B}^{2}\left(\mu_{F}^{-2}\right)_{a b} J_{L}^{H a} J_{R_{1}}^{b}$. where $\mu_{g}^{2}$ is the masstre oldewiyg gauge boson mass matrix, nnt the $J_{L(R)}^{\mu a}$ are the left ( $r$ ight)-handed broken sldeways currents. This interaction can be Flerz-transformed into the form of liq. (6).

To compute the effective potential, we note that the $s_{\text {-Invarlant vacium }}$ $|\Omega\rangle$ has the property $\left\langle\Omega\left|\bar{\psi}_{L r l}^{(\rho)} \psi_{R r^{\prime} j}^{(\sigma)}\right| \Omega\right\rangle=\delta^{\rho \sigma} \delta_{r r^{\prime}} \delta_{1 j} \Delta^{D}$. Therefore $s_{f}$-Invartm ance Inplies thit,

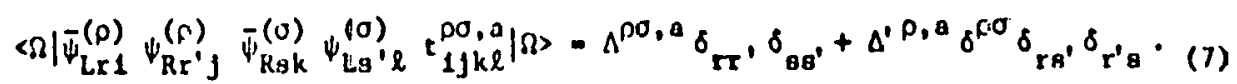


The second term on the right-hand side of Eq. (7) is $G_{f}$-invartant. Hence, the leading terw in the effective potentinl to

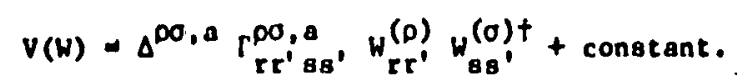

Hermiticlty and CP Invarlance of the effective Hamlitonian require

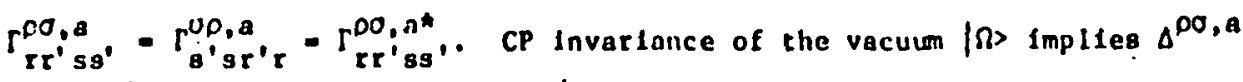
$-\Delta^{D \sigma, a^{*}}$. Therefore, $v(W)=V\left(W^{*}\right)$. In general, we expect that for some range of sideways gauge boson masses, the minlmum of $V(W)$ occurs for $\dot{w}$ complex, $y$ wa. Then the $m \ln 1$ mum 18 degentrate, and CP 18 spontaneously hroken. Now ve mInlalze $V(W)$ to determine the correct chlral perturbation $J C^{\prime}(W)$. $V(W)$ 1s stationary subject to the constralnt in Eq. (5) $1 f^{17}$

$$
\left(M^{(\rho)}-M^{(p)+}\right) \Delta^{\rho}=1\left(\nu_{11} T_{p}^{H}+\nu_{C} T_{p}^{C}\right) \mathbf{l} .
$$

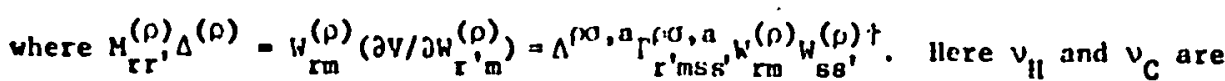
Lagrange multipllers. (Taking the trace of both sidcs of Eq. (9) and sumning

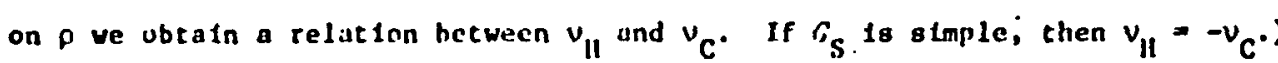

If we include contribut ions fron higher Jimension operaturs to $V(W)$, the condition for an extremum of $V(W)$ is stlll of the form given In Eq. (9), but with a modifled matrix $M^{(\rho)}$. For quarks, thits matrix $M^{(q)}$ differs from the "current-algebra" quark mass matrlx by approximately one part in $10^{9}$. This relation holds because the mass $\mathrm{m}_{\mathrm{c}}-300 \mathrm{MeV}$ at whicl color becomes strong $1 \mathrm{~g}$ small compared to the mass $\mathrm{m}_{11}-1 \mathrm{TeV}$ at wlich hypercolor becumes atrong.

Physics below $m_{11}-1$ TeV can he deseribed by an effective theory InvolvIng only quarky, leptone, gluons, electrowiak bisons, and pecudo-finldstone bogons. This effective Lagranglan ls obtalned by integrating out hypergluong and hyperfermions, as well as mashlve sldeways bosons. We must nlso sum up all hard forder $m_{11}$ ) gluon exchanges. A scrles of $G_{C}$-invartant operators. 1s generated. The operatury which contribute to the cffectivo potential are

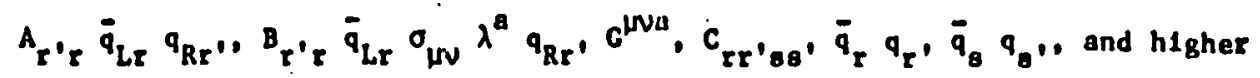
dimension operators. (Some operators can be ellminated by the equitions of motion.) The coeffictents $A, B, C$ depend on the hyperfermion $w^{(\rho)} \cdot \theta$. $A$ 1s the quirk mass matrix; it contributes $2 \Delta^{q} \operatorname{Re} \operatorname{Tr}\left(W^{(q)} A\right)$ to $V(u)$. Relative to this term, the contribution from four-quark operators ts auppressed by $\left(m_{c} / m_{H}\right)^{\prime} \sim 10^{-30}$. The operator $\bar{q}_{L} \sigma_{\mu \nu} \lambda^{a} q_{R} c^{\mu \nu a}$ 1s generated by graphs Involving one hard-gluon exchange: ${ }^{15}$ 1tH contribution 18 suppressed by $\left[a_{c}\left(m_{H}\right) / 2 n\right]\left(m_{c} / m_{H}\right)^{2} \sim 10^{-6}$. Hence, the part of $v(W)$ lnvolving $W^{(q)}$ 1s $2 \Delta^{q} \operatorname{Re} \operatorname{Tr} H^{(q)} \Lambda\left(1+0\left(10^{-9}\right)\right)$ and therefore $M^{(q)}-W^{(q)} \Lambda\left(1+0\left(10^{-9}\right)\right)$.

Equation (9) 18 solved by several heta of unltary matrices $W=\left(H^{(\rho)}\right)$. 'From all solutions, we choose the one (wr ones) which minimizes $V(W)$. Tho $W$ which minlolizes the effective potential wlil satisfy one of three conditions: (1) $H=W^{*}$. In this case, CP 18 not spontaneously brokell, and no CP violation occurs at all.

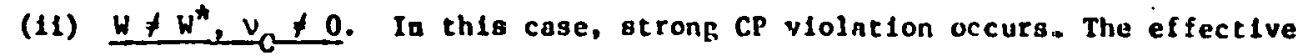
Hamiltonton contalins the CP-violating term $1\left(v_{c} / \Delta^{q}\right) \bar{q} 1 \gamma_{s} q$; a current algebra calculation of the neutron electric dipole moment $D_{n}$ yields $D_{n}-4 \times 10^{-16}\left(v_{C} / m_{u} \Delta^{q}\right) e c n$; where $m_{u}-5$ Met 18 the up quark mass. The natural scale of $v_{c} / \Delta^{q}$ is of order $m_{u}$ so we expect $D_{n}=10^{-15} \mathrm{em}$, whitet. exceeds the experimental bound ${ }^{10,20}$ by a facter of $10^{\circ}$.

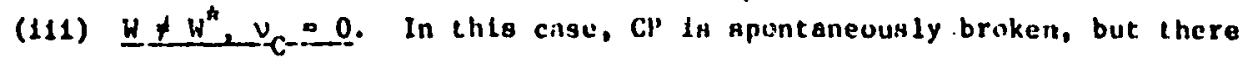
lo no large contribution to $D_{n}$. The coreffledents $B$ and $C$ have plisisen of order one, but alnce $M^{(q)}$ In herinltiall, $W^{(T)} A$ is hermltan up to corrections of order $10^{-9}$. The ant thermitlan part of the quark mass mutrix contributes of order $10^{-m_{e}}$ cin to $D_{n}$. $\Lambda$ simllar contribution cones from tho operator $\bar{q}_{L} \sigma_{\mu \nu} q_{R} F^{\mu \nu}$, where $F^{\mu \nu}$ is the photon Icld. Ita coefficient to expected to 
have a phase of order one and a magnituile $\left[\alpha_{C}\left(m_{H}\right) / 2 \pi\right]\left(m_{u} / \mathrm{m}_{H}^{2}\right) e=10^{-20} \mathrm{em} \cdot 15,21$ The Lagrange multiplier $v_{C}$ vanishes if the minimum of the effective potential rewains a stationary point when we rewove the constraint that $U_{A}(1)$ rotations with a color anomily are not allowed.

In any glven model, the dynamlcs determines which possibllity. is real1zed. Only models of type (11i) can have CP violating interactions conslatent with experiment.

In perturbation theory about the true chiral vacuum, the $W^{(\rho)}$ 's appear explicitly in the weak and sldeways currents. Minimizing the effectlve potental detcrmincs $W^{(\rho)}-W^{L(\rho) t_{W} R(n)}$ '(up tu possible diacrete degeneractes), but does not determlne $w^{L(f)}$ and $w^{R(p)}$ separately. For quarks, we define $w^{L(q)}$ and $w^{R(q)}$ by deglindling that the mass matrix $w^{(q)} \wedge$ be dlagonal. The quirk matrices $W^{L, R(q)}$ comate with electrle charge; there ara unftary matrices $w_{u}^{L}, R, w_{d}^{l}, R$ for up and down quarks. The kubayashi-Mnskawil mixlng mateix is $w_{u}^{L t} w_{d}^{l}$. If $1 t$ contains phases which cunnot be removed by redeflinting the phases of the quark flelds, then the wiak Interactions violate CP.

Mixinf. matrices eppear in the broken sideways currents also. Typlcally, phases in these matrices cannot he absorbed by redefinlng flelds, bccauge both left-handed and right-handed fermiuns trangform nontrivially under $f$. sideways gauge bosong can couple to flavor-clianging ncutral currents. If the operator csijsid occurs in the effective interaction. Im $C$ must be suppressed. If $\mathrm{C}$ 1s comparable to the coefficlent of the term which generates the down quark magg, 10,23 and arg C- $O(1)$, thls operator Induces a CP-violating part of

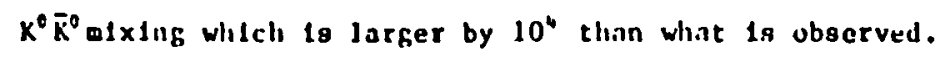

The effectlve lagranglan below 1 TeV cuntains pecudo-Coldstone bosons whose couplings to fermlons can le CP-vloliatlng. Exchange of these bosons can generate ollilweak CP violation."
Spontancous CP violation typlcally docs not occur if the sldeways inceraction is veciorial. But the sldeways Interaction must be nonjectortal to generate realistlc quark masses. ${ }^{3,4,2,3} \wedge$ loy model in whlch sportaneous $C P$ violation does occur has $G_{S}-S U(9) \times S U(y)$ and $G_{H}-S U(3)$. SU(j) is embcedded In the diagonal SU(9) such that the 9 transforms as $3+3+3$. The fermlons are In the representation $(1 ; 9)_{L}+(9,1)_{\dot{R}} \cdot$ (Anomalles can be eanceled without chang: Ing the resultes.) The flavor inroup is $G_{f}=S U(3) \times S U(3)$. If $V(W)$ 1s calculated to lowest order in $g_{s}^{?}$, it is miniafized by a complex mateix for a natural range of sldewilys gauge beson masses. The broken sldeways Interact lons violite $C P$, but tlic Lagrang: mutelpller v vanlshes.

He have proposed a natural mechanlism for generat Ing CP vlclation in a gauge theory whthout esementary scalar flolds or fermion bare nalsses. Although the atrung CP probjum is not autumat lcally solved, strorg Cl violation may be avolded in particular mudels. Howevhr,cP violation in the broken alde. ways Interactions is unavolJahle, If weak CP vinlation vecurs it all. Hence, If the electide.dipole moment of the neutron ts not discovered snon, 0 general appraach to CP violation whlch we ndvocate in this paper will become untenabla.

We thank $S$. Welnberg and K. Wllson for helpful conversotiuns. 'Thls work was supported in part by the Natlonal Srlence fuundation under Cirant No. PIIY77-22864, by the Department of Energy under Contruct No. DE-AC02-76ERO1545, and by the Alfred $P$. Sloan Foundition. 


\section{References}

- Present addrese: Department of Physlcs, Ohlo State UnIversity, Columbus, Oh10 43210.

1. S. KeInberg. Phys. Rev. D 13, 974 (1976).

2. Husskind, Phye. Rav. D 20,2619 (1979); S. Welnberg, Phys. Rev. D 19. $1277(1978)$

3. E. Elchten and K. Lane, Phys. Lett, 90R, 125 (1980).

4. S. Dimopoulus and L. Susskind, Nucl. Phys. B155, 237 (1979); S. Welnberg (unpublished).

S. R. Dashen, Phys. Re.v. D 3 , 1879 (1971).

6. C. 't Hooft, Phys. Rev. Lete. 37, 8 (1976); R. Jackiw and C. Rebb1, Phys. Rev. leete. 37, 172 (1976); C. Callan, R. Dashen, and D. Gross, Phys. Lett. 63B, $334(1976)$.

7. R. Peccel and H. Quinn, Phys. Rev. Lett. 38, 1440 (1977); S. NeInber8, Phys. Rev. Lett. 40, 223 (1978); F. Milcrek, Phys. Rev. Lete. 40, 279 (1978).

8. Here we disagree with previous propusals for solving the strong CP problew withln thces theorles; H. Pagels, Phya. Lett. 87B, 222 (1979), and Ref. 11.

9. M. Feskin (unpubllshed).

10. S. Dimopoulos, S. Raby and i. Susak1nd, "Tumbling Gauge Theorles," Stanford Preprint ITP-653 (1979).

11. 5. Dimopoulos and L: Susskind, "A Technlcolored Solution to the Strong CP Problem," Columbla Preprlint 79-0196 (1979).

12. The Hideways Interactiong are foolated from the CP-violating Interactons whlch generate the baryun excess In the early unlverse. Seo M. Yushlmura', Phys. Rev. Lett. 41, 281 (1978), 42, 746(e) (1979).
13. A model In which CP 10 opontaneously broken at 100 teV ls considered by B. Holdom, "A Realigte model with Dynamically Broken symetrles," Harvard Preprint IUUTP-80/A010.

14. Thla posstblltty was f1rat suggested by Dashen, Ref. S. See also T. D. Lee, Phys. Rev. D $\underline{8}, 1226$ (1973).

15. B. F.Ichten, K. Lane, and J. Presk111, In preparation.

16. If $n_{p}=2$ or 4, other forms occur, bu: our conclustons are not altered.

17. Thla generallzes a theoren of J. Nuyt.8, Phys. Rev. Lett. 26, 1604 (1971).

18. V. Lalunf, Phys. Rev. D 19, 2227 (1979); R. Crewther, P. Dt Vecchta, C. Venczlano, and E. Witten, Phys. Lett. B8B, 123 (1979).

19. W. B. Dress et al., Phys. Rev. D15. 9 (1977): 1. S. Altarev et al.. Leningrad Nucl. Phys. Inst. Preprint 430, I (1978).

20. N. F. Ramsey, Phys. Rpt. 43C, 409 (1978).

21. Rare processes ouch as $\mu+\mathrm{cr}, \mu+$ a conversion, and $K_{L}+$ He are also Induced by operators appcaring in the effective Lagranglan at raleo coaparable to present experimental upper 11 inlts.

22. M. Kobayazh1 and K. Maykawa, Prog. Theor. Phys, 49. 652 (19?3).

23. V. Balunl, "Quark Mass Spectrum and CP Nonconservation." IAS Preprint In preparation.

24. S. Weinber.8, Phys, Rev. Lett. 37, 657 (1975). See alно Lee, Rof. 14. 